\title{
Human Mesenchymal Stem Cells Reduce Lung Injury in Immunocompromised Mice but Not in Immunocompetent Mice
}

\author{
Rebecca Lim ${ }^{\mathrm{a}, \mathrm{b}}$ Phillipa Milton ${ }^{\mathrm{c}}$ Sean V. Murphy ${ }^{\mathrm{d}}$ Hayley Dickinson ${ }^{\mathrm{a}}$ \\ Siow Teng Chan ${ }^{a}$ Graham Jenkin ${ }^{a}$ b \\ aThe Ritchie Centre, Monash Institute for Medical Research, ${ }^{b}$ Department of Obstetrics and Gynaecology, Monash \\ Medical Centre, and 'Monash Immunology and Stem Cell Laboratories, Monash University, Clayton, Vic., Australia; \\ ${ }^{d}$ Institute for Regenerative Medicine, Wake Forest School of Medicine, Winston Salem, N.C., USA
}

\section{For editorial comment see p. 279}

\section{Key Words}

Mesenchymal stem cells • Plethysmography •

Lung inflammation

\begin{abstract}
Background: The immunomodulatory and immunosuppressive capacity of human mesenchymal stem cells (hMSC) is well recognized, but efficacies of hMSC in immunocompetent and immunocompromised animals have never been directly compared. Objectives: We aimed to compare the efficacy of hMSC in preventing bleomycin-induced lung injury in immunocompromised SCID and immunocompetent C57BI/6 mice. Methods: SCID and C57BI/6 mice were subjected to a single bolus intranasal instillation of bleomycin to induce lung injury. One million hMSC were administered intravenously $24 \mathrm{~h}$ following the induction of bleomycin lung injury. Results: hMSC xenotransplantation into SCID mice resulted in transient improvements in lung weight and tidal volume and to persistent improvement in inspiratory duty cycle, inspiratory flow rate and inspiration/expiration ratio. We did not observed protective effects in $\mathrm{C} 57 \mathrm{BI} / 6$ mice. This correlated with histological changes, where hMSC administration reduced Ashcroft scores, collagen deposition and inflammatory influx in the lungs of SCID mice, but not in those
\end{abstract}

of C57BI/6 mice. Conclusion: The application of hMSC for the treatment of acute and chronic lung injury is significantly affected by the immune status of the recipient. Lack of hMSCmediated repair observed in C57BI/6 mice was likely to be due to limitations of their immune privilege and differential priming of hMSC in immunocompetent versus immunocompromised hosts.

Copyright $\odot 2012$ S. Karger AG, Basel

\section{Introduction}

Human mesenchymal stem cells (hMSC) are a nonhematopoietic stem cell population which are readily accessible and can be easily expanded ex vivo on a clinical scale without altering their phenotype. The immuneprivileged, immunomodulatory and immunosuppressive capacity of hMSC has been investigated in studies of allogeneic skin implants in major histocompatibility complex (MHC) mismatched baboons [1] as well as their effect on cells of the immune system in vitro [2-5]. While a large body of work exists investigating the potential re-

R.L. and P.M. contributed equally to this paper.

\footnotetext{
Dr. Rebecca Lim

The Ritchie Centre, Monash Institute of Medical Research

27-31 Wright Street

Clayton, VIC 3168 (Australia)

E-Mail Rebecca.Lim@monash.edu
} 
parative and protective effects of hMSC in animal models of acute and chronic injuries [6-10], the efficacies of hMSC have never been compared between immunocompetent and immunocompromised animals.

The aim of this study was to compare the anti-inflammatory and antifibrotic effects of bone marrow-derived hMSC when administered $24 \mathrm{~h}$ after bleomycin challenge in immunocompromised SCID and immunocompetent $\mathrm{C} 57 \mathrm{Bl} / 6$ mice. We demonstrated that bone marrow-derived hMSC were able to reduce some aspects of the progression of bleomycin-induced lung injury in SCID mice but not in $\mathrm{C} 57 \mathrm{Bl} / 6$ mice. Unlike our previous study where we reported human amnion epithelial cell (hAEC)-mediated lung repair in bleomycin-injured $\mathrm{C} 57 \mathrm{Bl} / 6$ mice [11], it appears that bone marrow-derived hMSC have limited capacity to promote repair in immunocompetent mice following bleomycin-induced lung injury.

\section{Methods}

\section{Animals and Experimental Groups}

All experimental procedures were approved by the Monash University School of Biomedical Sciences Animal Ethics Committee and conducted in accordance with the Australian Code of Practice for the Care and Use of Animals for Scientific Purposes (2006). SCID and C57Bl/6 mice were randomly divided into four treatment groups with a total of 30 animals per strain. Eight- to 10 -week-old female mice weighing 18-21 g were randomly allocated to the following groups: saline + saline - intranasal (IN) instillation of saline and intravenous (IV) injection of saline $24 \mathrm{~h}$ later; bleomycin + saline - IN instillation of bleomycin ( 0.3 units per mouse) and IV injection of saline $24 \mathrm{~h}$ later; saline + hMSC IN instillation of saline and IV injection of 1 million hMSC $24 \mathrm{~h}$ later; bleomycin + hMSC - IN instillation of bleomycin and IV injection of 1 million hMSC $24 \mathrm{~h}$ later. Mice were culled either 7 or 14 days following IN bleomycin or saline instillation. Body weight, core temperature and basal lung function were recorded prior to commencement of experiments and at days 3, 7 and 14. SCID mice used in this study were mutant inbred albino mice of the genotype Tyrc, Prkdc scid and Igh-1b.

\section{Cell Culture}

The bone marrow-derived hMSC were obtained from the Tulane Center for Gene Therapy at Tulane University Health Sciences Center (New Orleans, La., USA). hMSC were cultured in $\alpha$-modified eagle medium (Gibco) with $16.5 \%$ (v/v) fetal bovine serum and antibiotics, maintained at $50-85 \%$ confluence and administered at passage 3 .

\section{Lung Function Testing}

Lung function was assessed using unrestrained whole-body barometric plethysmography at days $0,3,7$ and 14 , as previously described [12]. Waveform analysis was used to analyze the respiratory trace obtained from each animal, including the measurement of the change in pressure caused by the tidal movement of gas within the chamber, respiration rate (breaths/min), total breathing cycle time (seconds), inspiration time ( $\mathrm{T}_{\mathrm{i}}$, seconds) and expiration time ( $\mathrm{T}_{\mathrm{e}}$, seconds). Tidal volume $(\mathrm{ml})$ was calculated as described by Drorbaugh and Fenn [13]. Minute volume ( $\mathrm{ml} / \mathrm{min})$, inspiratory duty cycle (\%), inspiratory flow rate $(\mathrm{ml} / \mathrm{s})$ and the ratio of $\mathrm{T}_{\mathrm{i}}$ to $\mathrm{T}_{\mathrm{e}}\left(\mathrm{T}_{\mathrm{i}} / \mathrm{T}_{\mathrm{e}}\right.$ ratio) were also calculated.

\section{Tissue Collection}

Animals were euthanized by an intraperitoneal injection of $150 \mathrm{mg} / \mathrm{kg}$ Lethabarb (Virbac, Australia). The right lung was ligated at the right mainstem bronchus, excised, weighed to determine wet lung weight and processed for either RNA, protein or for the measurement of hydroxyproline. Upon excising the right lung, the trachea was exposed, cannulated and the left lung was instilled with $4 \%$ paraformaldehyde at $20 \mathrm{~cm} \mathrm{H}_{2} \mathrm{O}$ pressure and processed for histology.

\section{Hydroxyproline Assay}

The collagen content was assessed on lung tissue obtained at day 14 , where lung fibrosis is peak, by the measurement of hydroxyproline and by Sirius red immunostaining as previously described $[14,15]$.

\section{Ashcroft Score of Fibrosis}

Lung sections were scored for fibrosis using the Ashcroft scoring system on lung samples collected on day 14. Five-micronthick histological sections were cut throughout each left lung and stained with hematoxylin and eosin. Between 20 and 25 sequential fields of view encompassing the entire lung section $(\times 200$ magnification) were independently and blindly scored by three of the authors (S.T.C., R.L. and S.V.M.) for the severity of parenchymal lesions induced by bleomycin treatment according to the semiquantitative method previously described by Ashcroft [16].

\section{CD45 Immunohistochemistry}

Total inflammatory cell infiltration was determined using CD45 immunohistochemical staining on lungs collected on day 7. Immunohistochemical staining was performed with a monoclonal rat anti-mouse anti-CD45 antibody (560501, 1:100; BD Horizons, USA) where sections were incubated overnight at $4^{\circ} \mathrm{C}$. Tissue sections were then incubated with a biotinylated secondary antibody (goat anti-rat, AP1831b, 1:200; Chemicon, USA) for $1 \mathrm{~h}$ at room temperature before detection using the LSAB+ System HRP (Dako, Glostrup, Denmark) and liquid DAB substrate (Dako), then counterstained with hematoxylin. Ten non-overlapping images were captured using brightfield light microscopy at $\times 200$ magnification (AxioSkop, Zeiss, Germany). Images were converted to RGB analyzed using Metamorph bioanalytical software (Molecular Devices, USA) as previously described [11].

\section{Western Blotting}

Total protein was extracted from snap-frozen lungs obtained at day 7 , and $\alpha$-smooth muscle actin levels relative to $\beta$-actin were determined by Western blotting as previously described [16].

\section{RNA Isolation and Quantitative PCR}

Total RNA was isolated from snap-frozen lungs using TRIzol (Invitrogen) and converted to cDNA using Superscript III (Invitrogen). Quantitative PCR was performed as previously described [16]. Primers were directed against tumor necrosis factor- $\alpha$ 
Fig. 1. Effects of bleomycin and hMSC treatment on physiological and respiratory parameters of SCID mice. $\bigcirc=$ Saline controls; $\square$ = bleomycin + saline; $\mathbf{\square}=$ saline + hMSC; $\diamond=$ bleomycin + hMSC. a Body weights of bleomycin + saline and bleomycin + hMSC animals taken at days 3, 7 and 14 were significantly different to basal readings ( $\mathrm{p}<0.0001)$. b hMSC administration appeared to delay an increase in relative wet lung weight compared to the bleomycin + saline treatment group (**** $\mathrm{p}<0.0001)$. n.s. = Not significant; black = saline controls; light grey $=$ saline + hMSC; dark grey = bleomycin + saline; white $=$ bleomycin + hMSC. c Bleomycin reduced the tidal volume, which recovered towards basal levels following hMSC treatment at day 7. d This trend was also observed when the tidal volume was expressed relative to body weight, where hMSC administration markedly improved the tidal volume by day 7. e, $\mathbf{g}$ Bleomycin caused an increase in respiratory rate, which hMSC treatment did not resolve (e); however, hMSC administration maintained the inspiratory flow rate to levels comparable to controls (g). f, h The inspiratory duty cycle recovered to basal levels following hMSC treatment (f), and the breathing profile of SCID mice normalized to a symmetrical breathing pattern following hMSC treatment (h).

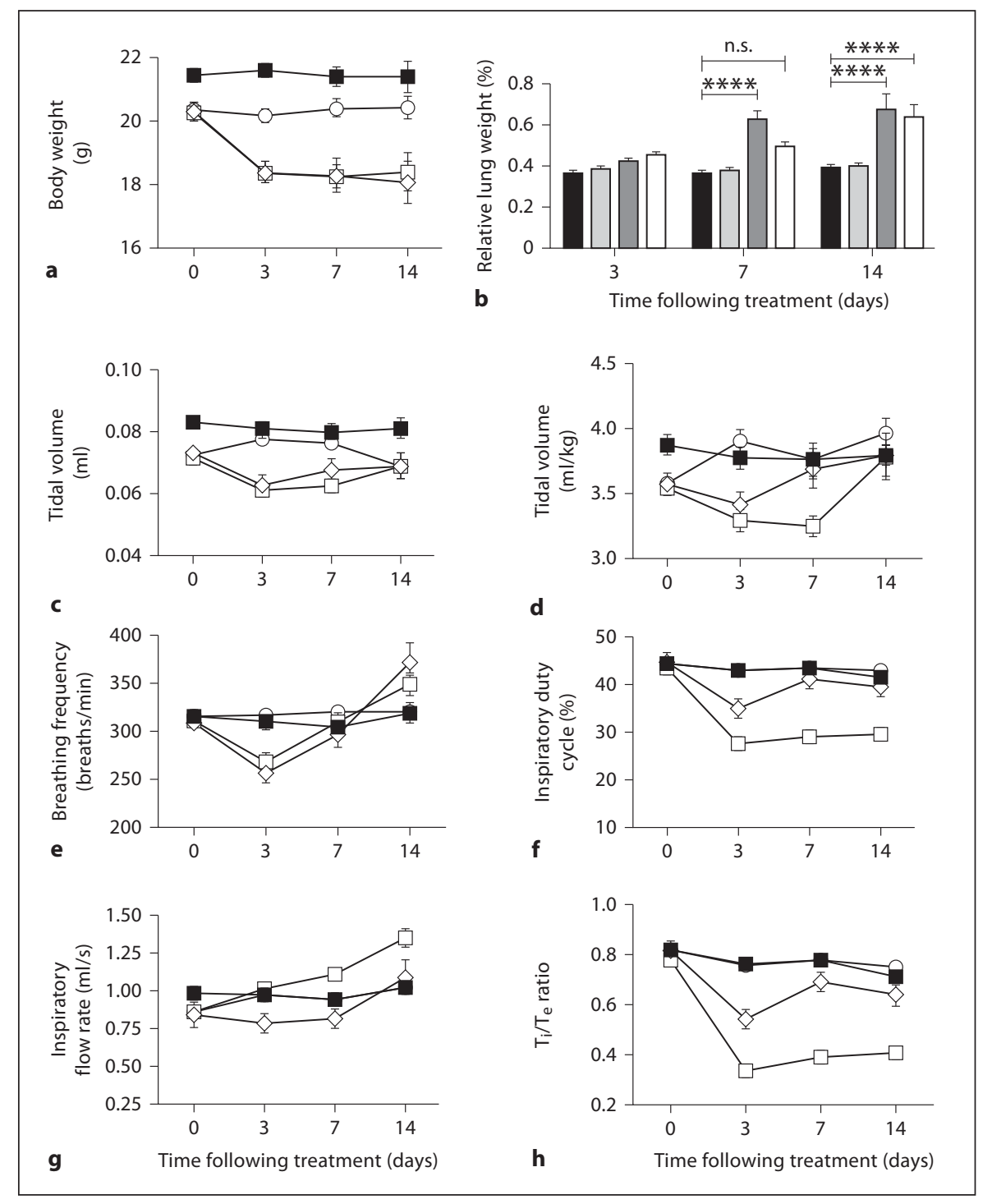

$(\operatorname{Tn} f \alpha)$, macrophage migration inhibitory factor (Mif), macrophage inflammatory protein-1 $\alpha(M i p-1 \alpha)$, transforming growth factor- $\beta(\operatorname{Tg} f \beta)$ and $18 S$. Primer sequences and annealing temperatures are available upon request. Gene expression of each marker was normalized to $18 S$.

\section{Data Analysis and Statistics}

Data were expressed as mean \pm SEM and statistical significance determined using statistical analysis software (GraphPad Prism, Graphpad Software Inc., USA). Body weight and lung function testing data were analyzed using the repeated measures NOVA followed by a Bonferroni post hoc test when significance was noted. Confidence intervals of $95 \%$ were assumed to be significant. Ashcroft scores, collagen content, Western blot and quantitative PCR data were analyzed using the one-way ANOVA followed by the Bonferroni post hoc test, and a 95\% confidence interval was assumed to be significant.

\section{Results}

\section{SCID Mice}

Whole Body and Lung Weights in SCID Mice

Body weight following bleomycin administration was comparable between animals in bleomycin treatment groups (fig. 1a). At day 7, the bleomycin + saline group had significantly heavier wet lung weight relative to body weight compared to the saline + saline group $(\mathrm{p}<0.001$; fig. 1b). There was no significant difference in relative wet lung weights between bleomycin + hMSC and saline + saline groups at day 7 . By day 14 , following bleomycin administration, there was no difference in the relative wet lung weights between the bleomycin + saline and the 
bleomycin + hMSC group; however, both were significantly higher than saline + saline-treated animals at the same time point $(\mathrm{p}<0.001$; fig. $1 b)$.

Tidal Volume and Respiratory Rate in SCID Mice

By day 3, bleomycin-injured mice had a reduced tidal volume, but by day 7 , the tidal volume of bleomycin + hMSC-treated mice recovered towards basal levels (fig. 1c). A similar trend was also observed for each treatment group when the tidal volume was considered relative to body weight, with overall differences also being significant ( $\mathrm{p}<0.05$; fig. $1 \mathrm{~d})$, and days 3 and 7 being significantly different to day $14(\mathrm{p}<0.05)$. At day 3, bleomycin-treated mice had reduced respiratory rates when compared to saline controls (fig. 1e).

Inspiratory Duty Cycle and Inspiratory Flow Rate in SCID Mice

The greatest reduction in inspiratory duty cycle by day 3 was observed in the bleomycin + saline group, compared to the bleomycin + hMSC group (fig. 1f). By day 7, the inspiratory duty cycle of SCID mice in the bleomycin + hMSC treatment group had partially recovered, while the inspiratory duty cycle of mice in the bleomycin + saline group remained low at day 7 (fig. 1f). By day 14, the inspiratory duty cycle of mice in the bleomycin + saline group was most profoundly reduced (fig. 1f). Immediately following and until day 14 after bleomycin administration, SCID mice in the bleomycin + saline group experienced a gradual increase in inspiratory flow rate (fig. 1g). The inspiratory flow rate was comparable between the bleomycin + hMSC and the saline + saline SCID mice from day 0 to 7 . From day 7 to 14 , the inspiratory flow rate for SCID mice in the bleomycin + hMSC group increased (fig. lg).

\section{$\mathrm{T}_{\mathrm{i}} / \mathrm{T}_{\mathrm{e}}$ Ratio in SCID Mice}

The $T_{i} / T_{e}$ ratio defines the contribution of each to the breathing cycle. SCID mice in the saline treatment groups had symmetrical breathing cycles with $\mathrm{T}_{i}$ and $\mathrm{T}_{\mathrm{e}}$ of essentially equal duration, as indicated by ratios close to 1.0 (fig. 1h). Prior to treatment, mice in the bleomycin treatment groups also had symmetrical breathing cycles. The $\mathrm{T}_{\mathrm{i}} / \mathrm{T}_{\mathrm{e}}$ ratio for the bleomycin treatment groups had decreased at day 3 , although this was most pronounced in the bleomycin + saline group. By day 7 , the $T_{i} / T_{e}$ ratio of mice in the bleomycin + hMSC group had recovered to within basal levels but this did not occur in the bleomycin + saline group and remained low to day 14 . The overall differences observed between treatment groups for the $\mathrm{T}_{\mathrm{i}} / \mathrm{T}_{\mathrm{e}}$ ratio were significant $(\mathrm{p}<0.0001)$.

hMSC in Immunocompromised and Immunocompetent Mice

\section{C57Bl/6 Mice}

Body Weight and Lung Weights in C57Bl/6 Mice

The overall differences observed in body weight were significant between bleomycin treatment groups and respective saline controls ( $p<0.0001$; fig. $2 \mathrm{a}$ ). Body weights of $\mathrm{C} 57 \mathrm{Bl} / 6$ mice in bleomycin treatment groups were comparable. By day 7, the weights of the bleomycin treatment groups were significantly reduced but subsequently recovered by day 14 . The wet lung weights relative to body weights were significantly different between bleomycin treatment groups and saline groups $(\mathrm{p}<$ 0.0001 ; fig. $2 b$ ). There were significant differences between both bleomycin treatment groups and the saline + saline group $(\mathrm{p}<0.001)$. At day 3 , there was no significant difference between $\mathrm{C} 57 \mathrm{Bl} / 6$ mice in the bleomycin + saline and bleomycin + hMSC treatment groups. By day 7 , relative wet lung weights for these groups were increased.

Tidal Volume and Respiratory Rate in C57Bl/6 Mice

Tidal volumes were significantly different between the bleomycin treatment groups and their respective saline control groups ( $p<0.001$; fig. $2 c)$. By day 3 , tidal volume of mice in the bleomycin + saline group was significantly lower, while the tidal volume of animals in the bleomycin + hMSC group remained comparable to basal levels. By day 7 , the tidal volume of mice in the bleomycin + saline group had recovered, while the bleomycin + hMSC group remained low but recovered by day 14 (fig. $2 \mathrm{~d}$ ).

The overall differences observed in respiratory rates between the bleomycin treatment groups and their respective saline control groups were significant $(\mathrm{p}<$ 0.0001 ; fig. 2e). By day 3, bleomycin-treated mice had decreased respiratory rates. From days 3 to 14, respiratory rates of mice in the bleomycin + hMSC group recovered towards basal levels. By contrast, respiratory rates of mice in the bleomycin + saline treatment group reached a nadir from days 3 to 7 at $206.92 \pm 4.46$ breaths $/ \mathrm{min}$ and recovered towards basal levels from days 7 to 14 when a rate of $275.44 \pm 17.18$ breaths/min was attained.

Inspiratory Flow Rate and Inspiratory Duty Cycle in C57Bl/6 Mice

The overall differences observed between the bleomycin treatment groups and their respective saline control groups for inspiratory duty cycle were significant $(\mathrm{p}<$ 0.0001 ; fig. $2 \mathrm{f}$ ). There was no significant difference in inspiratory duty cycle between the bleomycin treatment groups. From day 3 to 14, the inspiratory duty cycle of $\mathrm{C} 57 \mathrm{Bl} / 6$ mice in bleomycin treatment groups plateaued.

Respiration 2013;85:332-341 
Fig. 2. Effects of bleomycin and hMSC treatment on physiological and respiratory parameters of $\mathrm{C} 57 \mathrm{Bl} / 6$ mice compared to saline controls. $\bigcirc=$ Saline controls; $\square=$ bleomycin + saline; $\mathbf{\square}=$ saline + hMSC; $\diamond=$ bleomycin + hMSC. a C57Bl/6 mice showed no improvement in lung function following intravenous administration of hMSC. There was no difference in body weight for $\mathrm{C} 57 \mathrm{Bl} / 6$ mice in either the bleomycin + saline or the bleomycin + hMSC group. b Similarly, relative lung weights were comparable between the bleomycin treatment groups $\left({ }^{* * *} \mathrm{p}<0.001\right)$. Black $=$ saline controls; light grey = saline + hMSC; dark grey $=$ bleomycin + saline; white $=$ bleomycin + hMSC). c, d The tidal volumes were comparable as well. e Respiratory rates for mice in the bleomycin + saline and bleomycin + hMSC groups were reduced from day 3 , and hMSC exerted no therapeutic effect as both groups recovered towards basal levels by day 14. f-h The respiratory parameters of the inspiratory duty cycle (f), the inspiratory flow rate $(\mathbf{g})$ and the $T_{i} / T_{e}$ ratio $(\mathbf{h})$ were not improved either following hMSC administration to bleomycin-injured $\mathrm{C} 57 \mathrm{Bl} / 6$ mice/saline controls.

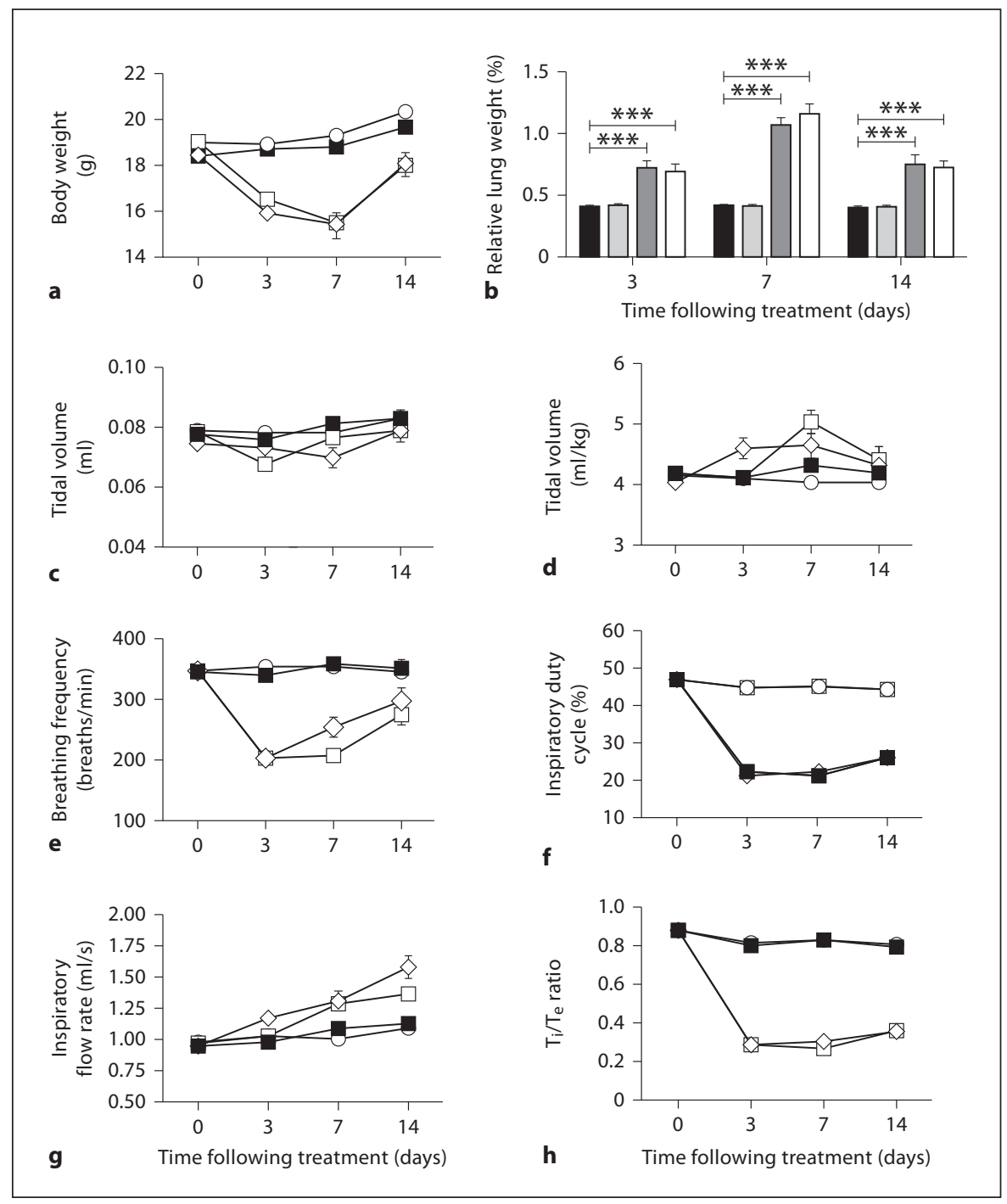

For the duration of the study period, animals in the saline groups maintained a consistent inspiratory duty cycle. The overall differences observed in the inspiratory flow rate were significantly different between the bleomycin treatment groups and their respective saline control groups ( $p<0.0001$; fig. 2 g), with all time points of analysis significantly different to basal readings $(\mathrm{p}<0.0001)$. The $\mathrm{C} 57 \mathrm{Bl} / 6$ mice in the bleomycin treatment groups exhibited a similar trend for inspiratory flow rate following their respective treatment regimes.

\section{$\mathrm{T}_{\mathrm{i}} / \mathrm{T}_{\mathrm{e}}$ Ratio in C57Bl/6 Mice}

The overall differences observed between the bleomycin treatment groups and their respective saline control groups for the $T_{i} / T_{e}$ ratio were significant $(p<0.0001$; fig. $2 \mathrm{~h}$ ), with all time points of analysis significantly different to basal readings $(\mathrm{p}<0.0001)$. Animals in the saline treatment groups had symmetrical breathing cycles with $\mathrm{T}_{\mathrm{i}}$ and $\mathrm{T}_{\mathrm{e}}$ times of essentially equal duration, as indicated by ratios close to 1.0. Prior to treatment, C57BL/6 mice in the bleomycin treatment groups also had symmetrical breathing cycles. Following their respective treatment regimes, mice in the bleomycin + saline and bleomycin + hMSC treatment groups exhibited a comparable trend in the $T_{i} / T_{e}$ ratio, which by day 3 , was significantly lower compared to that of the saline groups $(\mathrm{p}<$ 0.0001 ). From day 3 and for the remainder of the study period, the $\mathrm{T}_{\mathrm{i}} / \mathrm{T}_{\mathrm{e}}$ ratio for these mice did not recover towards basal levels but remained below 0.5 , indicating persistent asymmetric breathing. 

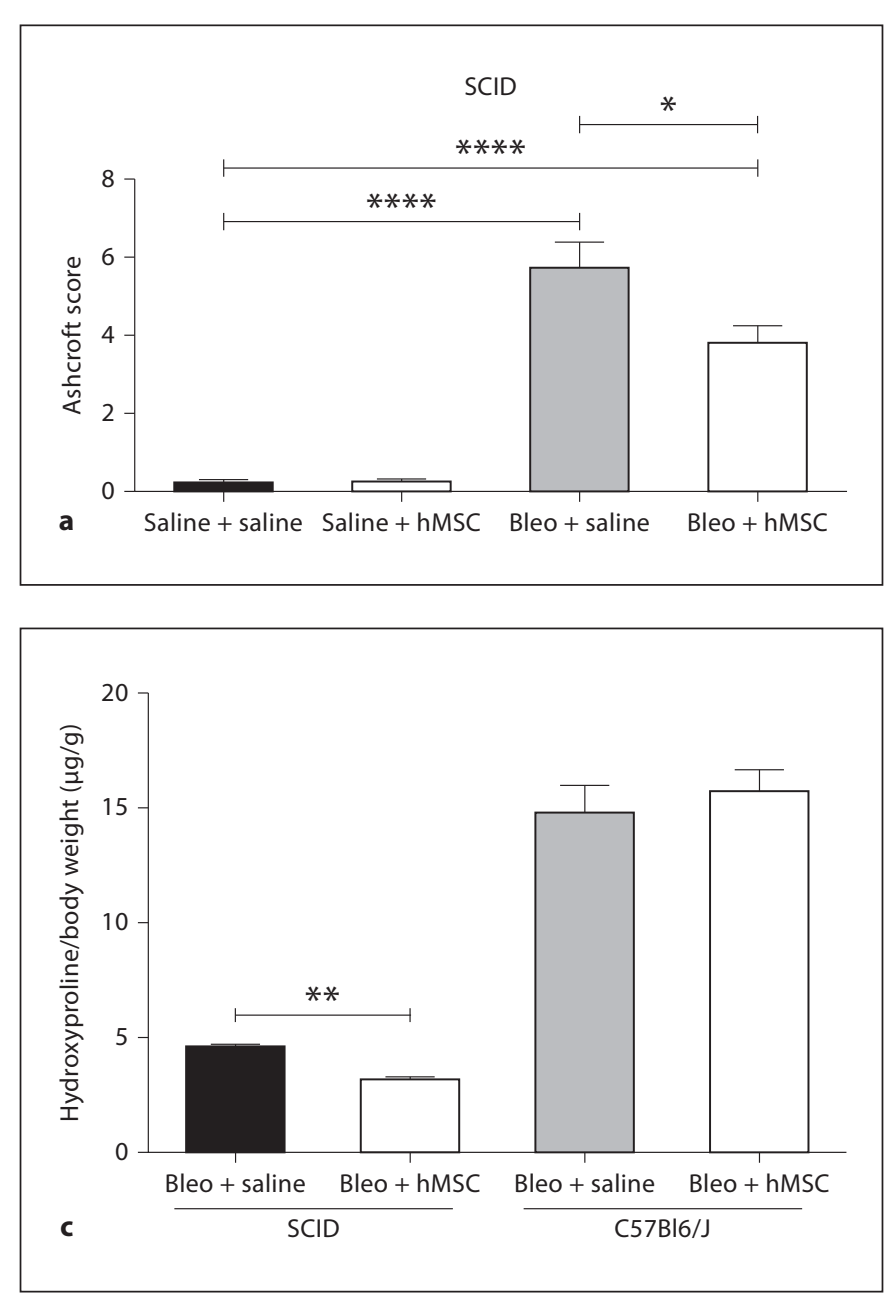

Fig. 3. Effects of bleomycin (Bleo) and hMSC treatment on lung inflammation and collagen deposition. a, b At day 14, bleomycintreated SCID and C57Bl/6 mice had significant Ashcroft scores compared to saline controls. Administration of hMSC significantly decreased Ashcroft scores in SCID but not in C57Bl/6 mice. However, Ashcroft scores were still significantly higher in the bleomycin + hMSC animals compared to the saline + saline ani-

\section{SCID and C57Bl/6 Mice}

Ashcroft Score for SCID and C57Bl/6 Mice

Ashcroft scores were significantly elevated in animals in the bleomycin + saline group compared to the saline + saline animals in both SCID and C57Bl/6 mice at day 14 ( $p<0.0001$; fig. 3a, b). Administration of hMSC to uninjured animals did not increase Ashcroft scores in either SCID or C57Bl/6 mice. However, hMSC administration reduced Ashcroft scores in bleomycin-injured animals in SCID mice ( $p<0.05$; fig. 3a). In contrast, hMSC administration had no effect on Ashcroft scores of C57Bl/6 mice (fig. 3b).

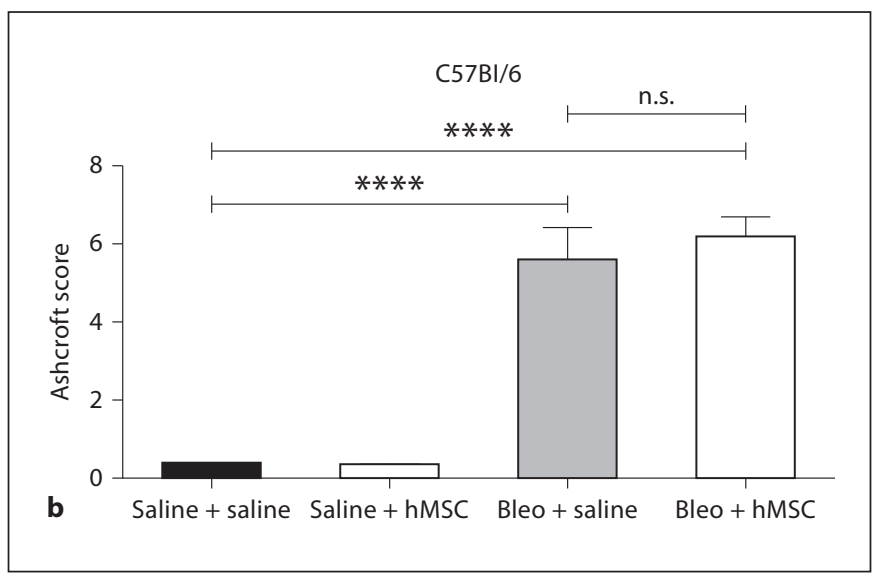

d

\begin{tabular}{|c|c|c|c|c|}
\hline \multirow{2}{*}{$\begin{array}{l}\text { Cyto- } \\
\text { kine }\end{array}$} & \multicolumn{2}{|l|}{ SCID } & \multicolumn{2}{|l|}{ C57BI/6 } \\
\hline & bleo + saline & bleo + hMSC & bleo + saline & bleo + hMSC \\
\hline MIF & $1.49 \pm 0.04$ & $1.13 \pm 0.21$ & $9.55 \pm 2.50$ & $2.19 \pm 0.56^{* *}$ \\
\hline MIP-1 $1 \alpha$ & $4.69 \pm 0.01$ & $2.66 \pm 0.36^{*}$ & $18.39 \pm 4.95$ & $7.33 \pm 1.41^{*}$ \\
\hline TGF- $\beta$ & $8.41 \pm 0.59$ & $39.16 \pm 9.23^{*}$ & $2.61 \pm 0.51$ & $1.56 \pm 0.27^{*}$ \\
\hline TNF- $\alpha$ & $2.43 \pm 0.16$ & $4.27 \pm 2.00$ & $40.38 \pm 5.73$ & $18.34 \pm 5.44^{*}$ \\
\hline
\end{tabular}

mals $\left({ }^{*} \mathrm{p}<0.05,{ }^{* * *} \mathrm{p}<0.0001\right)$. n.s. $=$ Not significant. $\mathbf{c}$ The hydroxyproline content was significantly reduced following hMSC administration in the lungs of SCID mice, but this was unchanged in $\mathrm{C} 57 \mathrm{Bl} / 6$ mice $\left.{ }^{* *} \mathrm{p}<0.01\right)$. d Administration of hMSC reduced gene expression of MIP-1 $\alpha$ with a concurrent increase in TGF- $\beta$ in SCID mice $\left({ }^{*} \mathrm{p}<0.05\right)$. In C57Bl/6 mice, hMSC administration reduced gene expression of MIF, MIP- $1 \alpha$, TGF- $\beta$ and TNF- $\alpha$.

Hydroxyproline Content Relative to Body Weight for SCID and $\mathrm{C} 57 \mathrm{Bl} / 6$ Mice

The hydroxyproline content was approximately 3 -fold greater in $\mathrm{C} 57 \mathrm{Bl} / 6$ mice compared to SCID mice. Additionally, in SCID mice, the hydroxyproline content relative for body weight was lower in the bleomycin + hMSC compared to the bleomycin + saline group ( $p<0.01$; fig. 3c). There was no significant difference in hydroxyproline content relative to body weight between the bleomycin + hMSC and bleomycin + saline groups for C57Bl/6 mice (fig. 3c). 

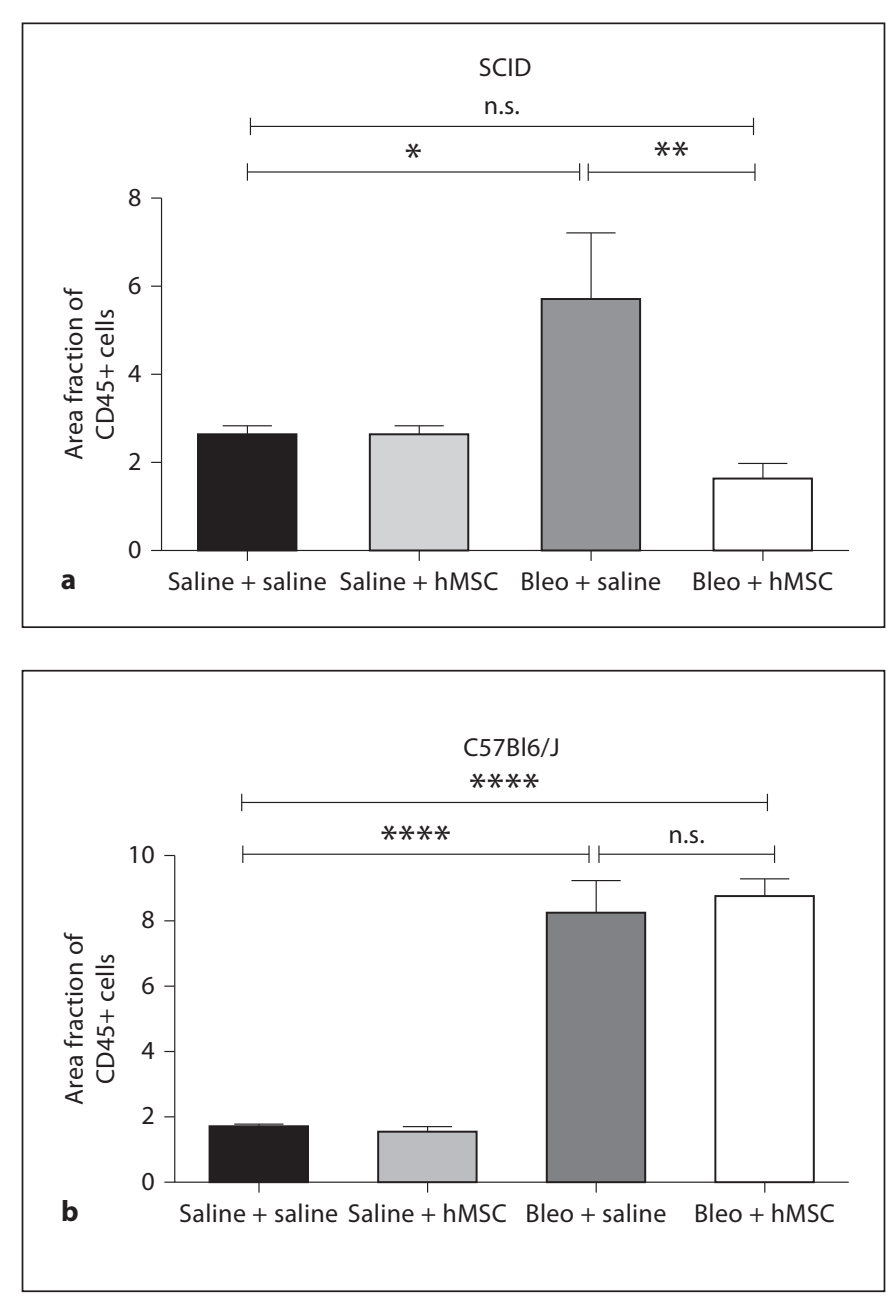

Fig. 4. Effect of bleomycin (Bleo) and hMSC treatment on lung inflammatory cell infiltrate. a At day 7, with lung inflammation peaks following bleomycin lung injury, numbers of CD45+ cells were approximately double in SCID mice. The influx of inflammatory cells was significantly decreased in bleomycin + hMSC animals to levels that were comparable to those of saline + saline controls $\left({ }^{*} \mathrm{p}<0.05,{ }^{* *} \mathrm{p}<0.01\right)$. b Bleomycin injury increased inflammatory cell infiltration, but hMSC did not mitigate the influx of CD45+ cells in C57Bl/6 mice $\left({ }^{* * *} \mathrm{p}<0.0001\right)$.

Changes to Proinflammatory Cytokines in SCID and C57Bl/6 Mice

In SCID mice, compared to bleomycin + saline, bleomycin + hMSC treatment resulted in significant reduction in Mip-1 $\alpha(\mathrm{p}<0.05)$, with a concurrent increase in $\operatorname{Tg} f \beta(\mathrm{p}<0.05)$ and no significant differences in expression of Mif and Tnf $\alpha$. In C57Bl/6 mice, hMSC treatment of bleomycin-injured mice resulted in significantly reduced gene expression of $\operatorname{Mif}(\mathrm{p}<0.01), \operatorname{Mip}-1 \alpha(\mathrm{p}<0.05)$, $\operatorname{Tg} f \beta(\mathrm{p}<0.05)$ and $\operatorname{Tnf} \alpha(\mathrm{p}<0.05)$.
Inflammatory Cell Influx and Collagen Deposition in SCID and C57Bl/6 Mice

The bleomycin insult doubled CD45+ cells in the lungs of SCID mice ( $p<0.05$; fig. 4a). Similarly, CD $45+$ cells were increased approximately 4 -fold in bleomycin-exposed C57Bl/6 mice ( $\mathrm{p}<0.0001$; fig. $4 \mathrm{~b}$ ). hMSC administration was able to reduce inflammatory cell influx in SCID mice to levels that were not significantly different to those of the saline + saline controls $(\mathrm{p}<0.01$; fig. $4 \mathrm{a})$. In contrast, hMSC administration did not significantly alter inflammatory cell infiltration in bleomycin-challenged C57Bl/6 mice ( $p>0.05$; fig. 4b).

\section{Discussion}

This is the first study comparing the reparative effects of bone marrow-derived hMSC on respiratory physiology, as well as on lung inflammation and fibrosis in immunocompromised SCID and immunocompetent $\mathrm{C} 57 \mathrm{Bl} / 6$ mice. Intravenous hMSC administration into bleomycin-injured SCID mice improved some, but not all, physiological lung function parameters. In contrast, when hMSC were intravenously administered to C57Bl/6 mice, there was no improvement in lung function, inflammation or fibrosis following bleomycin administration. Interestingly, reduction in gene expression of proinflammatory cytokines in C57Bl/6 mice was not associated with lung repair, while improvement in SCID mice was independent of proinflammatory cytokine gene expression.

In the present study, we report that pulmonary function is adversely affected following bleomycin administration, where significant changes in volumetric and breathing cycle parameters are observed. Bleomycintreated mice experienced a loss in respiratory function, as characterized by a decrease in tidal volume and a rapid, shallow breathing pattern. This was likely due to lung vagal afferents, which have been previously reported to cause this breathing pattern following bleomycin challenge in rats as well as pulmonary edema and decreased lung compliance due to fibrosis. These collectively impact on the oscillatory mechanics of the lung and result in altered respiratory parameters of the inspiratory flow rate, the inspiratory duty cycle and the ratio of $\mathrm{T}_{\mathrm{i}} / \mathrm{T}_{\mathrm{e}}$ as observed in this current study.

The efficacy of MSC to aid in repair and reduce inflammation remains a subject of debate. The reparative effects of bone marrow hMSC in SCID mice, as observed in this study, through the recovery of a number of respi- 
ratory parameters, are in keeping with current literature where others have reported the efficacy of hMSC isolated from umbilical cord to attenuate lung injury induced by bleomycin in SCID mice [17]. In contrast, bone marrowderived hMSC failed to mitigate inflammation and fibrosis in immunocompetent $\mathrm{C} 57 \mathrm{Bl} / 6$ mice, despite the reported immune privilege status of hMSC [18]. Although it is this characteristic of immune privilege that has quickly progressed the clinical use of hMSC for prevention of graft-versus-host disease when cotransplanted with human leukocyte antigen (HLA)-mismatched allogeneic hematopoietic stem cells $[19,20]$. This is not the first study to show the limitations of hMSC as a potential therapeutic agent. Puymirat et al. [21] reported no improvement in cardiac function following transplantation of bone marrow-derived hMSC in an immunocompetent rat model of myocardial infarction. These authors argued that hMSC have the capacity to act as antigen-presenting cells and remain susceptible to natural killer (NK) cellmediated cytolysis [22]. Furthermore, in other models, MSC have been reported to lose their apparent immune privilege following in vivo transplantation due to increased MHC II expression upon differentiation [23].

We believe that there are at least three possible explanations for the difference observed in reparative effects between the two strains of mice used in this current study. Firstly, it is possible that xenogeneically transplanted hMSC were rejected by $\mathrm{C} 57 \mathrm{Bl} / 6$ mice, while such immune rejection was limited in SCID mice. MSC have been previously reported to undergo rejection following allogeneic MHC-mismatched injection into immunocompetent $\mathrm{BALB} / \mathrm{c}$ and $\mathrm{C} 57 \mathrm{Bl} / 6$ mice $[24,25]$.

Secondly, differences in immunological composition between strains of mice may have resulted in differential priming of hMSC. There is a growing body of evidence that immunosuppressive properties of MSC are dependent on chemokines and nitric oxide production, as well as on priming by TNF- $\alpha$ and interferon (IFN)- $\gamma$ [26]. The immune-privileged nature of hMSC has been attributed to soluble factors released only after priming, rather than to constitutive expression [27]. SCID mice used in this study were derived from a C.B-17 background. Historically, C.B-17 SCID mice have been shown to have fewer infiltrating lymphocytes and lower levels of interleukin (IL)-2, TNF- $\alpha$ and IFN- $\gamma$ mRNA transcripts compared to $\mathrm{C} 57 \mathrm{Bl} / 6$ mice, following bleomycin-induced lung injury [28]. This may have contributed to different priming signals to the hMSC administered in SCID mice when compared to $\mathrm{C} 57 \mathrm{Bl} / 6$ mice. Investigations into hMSC priming following transplantation should be performed

hMSC in Immunocompromised and Immunocompetent Mice in future studies since the impact of hMSC priming on repair and immune modulation may be profoundly different depending on the circulating cytokines of the recipient or the cytokine environment within the transplanted tissues.

Thirdly, differences in cytokine response between the two strains of mice used in this study may have resulted in differential macrophage polarization. In vitro studies on MSC macrophage interactions suggest that MSC may mediate repair by polarizing macrophages to a pro-reparative M2 phenotype, which suppress the production of TNF- $\alpha$, IFN- $\gamma$, IL-6, IL-12p70 and concurrently increase the production of IL-10 and IL-12p40 [29, 30]. Taken together with previous reports of impaired lymphocyte infiltration and attenuated proinflammatory cytokine expression after bleomycin insult [28], it is likely that SCID mice had fewer M1 polarized macrophages in their lungs compared to $\mathrm{C} 57 \mathrm{Bl} / 6$ mice. With an increased total CD45+ infiltrate and a potentially predominant M1 macrophage population in $\mathrm{C} 57 \mathrm{Bl} / 6$ mice [unpubl. data], it is possible that xenotransplanted hMSC were unable to influence the polarity of macrophages to an extent necessary for repair.

Relative gene expression of $\operatorname{Tg} f \beta$ was elevated in SCID mice following hMSC treatment. However, this did not translate to increased fibrosis that would be expected since $\operatorname{Tg} f \beta$ is a potent activator of myofibroblasts and its mRNA and protein expression has been previously shown to be affected by bleomycin [31]. Similarly, reduction in relative gene expression of Mif, Mip- $1 \alpha$ and $T g f \beta$ in $\mathrm{C} 57 \mathrm{Bl} / 6$ mice following hMSC administration did not correlate with reduction in inflammation and fibrosis or with improvement in physiological breathing parameters despite these factors having previously been reported to play vital roles in the progression of bleomycin-induced inflammation and fibrosis. Together, these data suggest that while hMSC xenotransplantation into immunocompetent mice could affect cytokine gene expression, this was insufficient to mitigate disease progression in this model.

Xenotransplantation of hMSC from umbilical cord blood improved hyperoxia-induced lung injury but not survival rates of newborn Sprague-Dawley rat pups [32]. A key difference between umbilical cord blood-derived hMSC used by Chang et al. [32] and the bone marrowderived hMSC used in this current study is the constitutive surface expression of HLA-G on the majority of the umbilical cord blood hMSC [33]. In contrast, most bone marrow hMSC only express the soluble form of HLA-G [34]. hAEC possess stem cell-like properties which include multilineage differentiation potential, surface ex- 
pression of traditional stem cell markers and, of particular interest to this paper, constitutively high levels of HLA-G expression [35]. hAEC have been previously reported to mitigate bleomycin-induced lung injury in immunocompetent [11] and immunocompromised [36] animals. The apparent differences between the efficacy of hAEC and bone marrow-derived hMSC to mitigate bleomycin-induced lung injury in immunocompetent mice may well be attributed to the relative expression of HLA-G. HLA-G exerts a strong immunosuppressive effect on proliferation and activation of $\mathrm{T}$ and NK cells. Trogocytosis, a process that involves the internalization of membrane-bound HLA-G by dendritic cells, NK cells and effector $\mathrm{T}$ cells, converts them to a regulatory cell type through the transient expression of HLA-G [37], a molecule that is critical to tolerance and graft acceptance [38] as well as to lung repair [39]. While this mechanism of action has not been studied to date, it may explain the bystander effect previously documented in stem cells as well as account for differences in the efficacy of stem cells from different sources.

This study addressed the limitations of bone marrowderived hMSC by comparing their effects on immunocompromised and immunocompetent mice histologically and physiologically. We have previously reported on functional recovery in respiratory dynamics of hAEC xenotransplantation in bleomycin-injured C57Bl/6 mice [11], but we were unable to detect any changes to respiratory function following hMSC administration in this current study. However, we did observe reparative effects of hMSC on SCID mice. These findings are important when considering the clinical use of MSC where autologous transplantation may not always be feasible. If the immune-privileged status of MSC only allows immune tolerance between allogeneic donors but does not contribute to repair, this information needs to be taken into consideration prior to embarkation on clinical use. There is evidence that hMSC develop immunogenicity following allogeneic transplantation, resulting in the elimination and eventual loss of beneficial effects [40]. Further studies looking into the differential priming of hMSC between the two strains of animals are likely to uncover mechanisms by which favorable effects of hMSC are controlled. Findings from our current study also suggest that efficacy of hMSC therapy relies on intricate interactions with the immune system and may be more complex than simple immune suppression.

\section{Acknowledgments}

This research was partially funded by an NHMRC Project Grant No. 491145 and the Victorian Government's Operational Infrastructure Support Program. Dr. R. Lim is supported by a fellowship award from the Royal Australian and New Zealand College for Obstetricians and Gynecologists, Dr. P.L. Milton was receptor of an Australian Stem Cell Centre Premier Scholarship, and Dr. H. Dickinson is supported by an ARC Australian PostDoctoral Research Fellowship.

\section{Financial Disclosure and Conflicts of Interest}

The authors declare no conflicts of interest.

\section{References}

1 Bartholomew A, Sturgeon C, Siatskas M, Ferrer K, McIntosh K, Patil S, Hardy W, Devine S, Ucker D, Deans R, Moseley A, Hoffman R: Mesenchymal stem cells suppress lymphocyte proliferation in vitro and prolong skin graft survival in vivo. Exp Hematol 2002;30:42-48.

-2 Le Blanc K: Immunomodulatory effects of fetal and adult mesenchymal stem cells. Cytotherapy 2003;5:485-489.

-3 Rasmusson I, Ringden O, Sundberg B, Le Blanc K: Mesenchymal stem cells inhibit the formation of cytotoxic T lymphocytes, but not activated cytotoxic $\mathrm{T}$ lymphocytes or natural killer cells. Transplantation 2003;76: 1208-1213.

4 Saito T, Kuang JQ, Bittira B, Al-Khaldi A, Chiu RC: Xenotransplant cardiac chimera: immune tolerance of adult stem cells. Ann Thorac Surg 2002;74:19-24, discussion 24.
5 Sotiropoulou PA, Perez SA, Gritzapis AD, Baxevanis CN, Papamichail M: Interactions between human mesenchymal stem cells and natural killer cells. Stem Cells 2006;24:7485.

6 Bonfield TL, Koloze M, Lennon DP, Zuchowski B, Yang SE, Caplan AI: Human mesenchymal stem cells suppress chronic airway inflammation in the murine ovalbumin asthma model. Am J Physiol Lung Cell Mol Physiol 2010;299:L760-L770.

7 Kim ES, Chang YS, Choi SJ, Kim JK, Yoo HS, Ahn SY, Sung DK, Kim SY, Park YR, Park WS: Intratracheal transplantation of human umbilical cord blood-derived mesenchymal stem cells attenuates Escherichia coli-induced acute lung injury in mice. Respir Res 2011;12:108.
Liang L, Dong C, Chen X, Fang Z, Xu J, Liu M, Zhang X, Gu DS, Wang D, Du W, Zhu D, Han ZC: Human umbilical cord mesenchymal stem cells ameliorate mice trinitrobenzene sulfonic acid (TNBS)-induced colitis. Cell Transplant 2011;20:1395-1408.

9 Liu Y, Mu R, Wang S, Long L, Liu X, Li R, Sun J, Guo J, Zhang X, Yu P, Li C, Huang Z, Wang D, Li H, Gu Z, Liu B, Li Z: Therapeutic potential of human umbilical cord mesenchymal stem cells in the treatment of rheumatoid arthritis. Arthritis Res Ther 2010; 12:R210.

10 Zhou B, Yuan J, Zhou Y, Ghawji M Jr, Deng YP, Lee AJ, Nair U, Kang AH, Brand DD, Yoo TJ: Administering human adipose-derived mesenchymal stem cells to prevent and treat experimental arthritis. Clin Immunol 2011; 141:328-337. 
11 Murphy S, Lim R, Dickinson H, Acharya R, Rosli S, Jenkin G, Wallace E: Human amnion epithelial cells prevent bleomycin-induced lung injury and preserve lung function. Cell Transplant 2010;20:909-923.

12 McGregor HP, Westcott K, Walker DW: The effect of prenatal exposure to carbon monoxide on breathing and growth of the newborn guinea pig. Pediatr Res 1998;43:126-131.

13 Drorbaugh JE, Fenn WO: A barometric method for measuring ventilation in newborn infants. Pediatrics 1955;16:81-87.

14 Woessner JF Jr: The determination of hydroxyproline in tissue and protein samples containing small proportions of this imino acid. Arch Biochem Biophys 1961;93:440447.

-15 Escolar JD, Tejero C, Escolar MA, Montalvo F, Garisa R: Methodological contributions for the morphometric study of the lung: approximation to the ideal sample size and quantification of collagen fiber. Anat Rec 1997;247:501-511.

16 Murphy S, Chin SS, Tan JL, Chan S, Jenkin G, Wallace EM, Lim R: Human amnion epithelial cells do not abrogate pulmonary fibrosis in mice with impaired macrophage function. Cell Transplant 2011 DOI: 10.3727/096368911X601028.

17 Moodley Y, Atienza D, Manuelpillai U, Samuel CS, Tchongue J, Ilancheran S, Boyd R, Trounson A: Human umbilical cord mesenchymal stem cells reduce fibrosis of bleomycin-induced lung injury. Am J Pathol 2009; 175:303-313

18 Uccelli A, Pistoia V, Moretta L: Mesenchymal stem cells: a new strategy for immunosuppression? Trends Immunol 2007;28:219226.

19 Baron F, Lechanteur C, Willems E, Bruck F, Baudoux E, Seidel L, Vanbellinghen JF, Hafraoui K, Lejeune M, Gothot A, Fillet G, Beguin Y: Cotransplantation of mesenchymal stem cells might prevent death from graft-versus-host disease (GVHD) without abrogating graft-versus-tumor effects after HLA-mismatched allogeneic transplantation following nonmyeloablative conditioning. Biol Blood Marrow Transplant 2010;16:838-847.

20 Dazzi F, Marelli-Berg FM: Mesenchymal stem cells for graft-versus-host disease: close encounters with $\mathrm{T}$ cells. Eur J Immunol 2008;38:1479-1482.

-21 Puymirat E, Geha R, Tomescot A, Bellamy V, Larghero J, Trinquart L, Bruneval P, Desnos M, Hagege A, Puceat M, Menasche P: Can mesenchymal stem cells induce tolerance to cotransplanted human embryonic stem cells? Mol Ther 2009;17:176-182.
22 Spaggiari GM, Capobianco A, Becchetti S, Mingari MC, Moretta L: Mesenchymal stem cell-natural killer cell interactions: evidence that activated NK cells are capable of killing MSCs, whereas MSCs can inhibit IL-2-induced NK-cell proliferation. Blood 2006;107: 1484-1490.

23 Liu H, Kemeny DM, Heng BC, Ouyang HW, Melendez AJ, Cao T: The immunogenicity and immunomodulatory function of osteogenic cells differentiated from mesenchymal stem cells. J Immunol 2006;176:2864-2871.

24 Nauta AJ, Westerhuis G, Kruisselbrink AB, Lurvink EG, Willemze R, Fibbe WE: Donorderived mesenchymal stem cells are immunogenic in an allogeneic host and stimulate donor graft rejection in a nonmyeloablative setting. Blood 2006;108:2114-2120.

25 Eliopoulos N, Stagg J, Lejeune L, Pommey S, Galipeau J: Allogeneic marrow stromal cells are immune rejected by MHC class I- and class II-mismatched recipient mice. Blood 2005;106:4057-4065.

26 Prasanna SJ, Gopalakrishnan D, Shankar SR, Vasandan AB: Pro-inflammatory cytokines, IFNgamma and TNFalpha, influence immune properties of human bone marrow and Wharton jelly mesenchymal stem cells differentially. PLoS One 2010;5:e9016.

27 Groh ME, Maitra B, Szekely E, Koc ON: Human mesenchymal stem cells require monocyte-mediated activation to suppress alloreactive T cells. Exp Hematol 2005;33:928934.

28 Helene M, Lake-Bullock V, Zhu J, Hao H, Cohen DA, Kaplan AM: T cell independence of bleomycin-induced pulmonary fibrosis. Leukoc Biol 1999;65:187-195.

29 Kim J, Hematti P: Mesenchymal stem celleducated macrophages: a novel type of alternatively activated macrophages. Exp Hematol 2009;37:1445-1453.

30 Maggini J, Mirkin G, Bognanni I, Holmberg J, Piazzon IM, Nepomnaschy I, Costa H, Canones C, Raiden S, Vermeulen M, Geffner JR: Mouse bone marrow-derived mesenchymal stromal cells turn activated macrophages into a regulatory-like profile. PLoS One 2010;5:e9252.

- 31 Coker RK, Laurent GJ, Shahzeidi S, Lympany PA, du Bois RM, Jeffery PK, McAnulty RJ: Transforming growth factors-beta 1 , -beta 2 , and -beta 3 stimulate fibroblast procollagen production in vitro but are differentially expressed during bleomycin-induced lung fibrosis. Am J Pathol 1997;150:981-991.
32 Chang YS, Oh W, Choi SJ, Sung DK, Kim SY, Choi EY, Kang S, Jin HJ, Yang YS, Park WS: Human umbilical cord blood-derived mesenchymal stem cells attenuate hyperoxia-induced lung injury in neonatal rats. Cell Transplant 2009;18:869-886.

- 33 La Rocca G, Anzalone R, Corrao S, Magno F Loria T, Lo Iacono M, Di Stefano A, Giannuzzi P, Marasa L, Cappello F, Zummo G, Farina F: Isolation and characterization of Oct-4+/HLA-G+ mesenchymal stem cells from human umbilical cord matrix: differentiation potential and detection of new markers. Histochem Cell Biol 2009;131:267282

34 Selmani Z, Naji A, Zidi I, Favier B, Gaiffe E, Obert L, Borg C, Saas P, Tiberghien P, RouasFreiss N, Carosella ED, Deschaseaux F: Human leukocyte antigen-G5 secretion by human mesenchymal stem cells is required to suppress $\mathrm{T}$ lymphocyte and natural killer function and to induce CD4+CD25high FOXP3+ regulatory T cells. Stem Cells 2008; 26:212-222.

35 Ilancheran S, Michalska A, Peh G, Wallace EM, Pera M, Manuelpillai U: Stem cells derived from human fetal membranes display multilineage differentiation potential. Biol Reprod 2007;77:577-588.

36 Moodley Y, Ilancheran S, Samuel C, Vaghjiani V, Atienza D, Williams ED, Jenkin G, Wallace E, Trounson A, Manuelpillai U: Human amnion epithelial cell transplantation abrogates lung fibrosis and augments repair. Am J Respir Crit Care Med 2010;182:643651.

37 LeMaoult J, Krawice-Radanne I, Dausset J, Carosella ED: HLA-G1-expressing antigenpresenting cells induce immunosuppressive CD4+ T cells. Proc Natl Acad Sci USA 2004; 101:7064-7069.

-38 Nasef A, Mathieu N, Chapel A, Frick J, Francois S, Mazurier C, Boutarfa A, Bouchet S, Gorin NC, Thierry D, Fouillard L: Immunosuppressive effects of mesenchymal stem cells: involvement of HLA-G. Transplantation 2007:84:231-237.

39 Ling TY, Wu MS, Hsieh YT, Hsu JC, Lai HC, Peng FC, Jhuang JY, Chen YC: HLA-G molecules are important in alleviation of acute lung injury by placenta chorion mesenchymal stem cells (pcMSCs) therapy in mice model. J Stem Cell Reg Med 2011;7:147.

40 Huang XP, Sun Z, Miyagi Y, McDonald Kinkaid H, Zhang L, Weisel RD, Li RK: Differentiation of allogeneic mesenchymal stem cells induces immunogenicity and limits their long-term benefits for myocardial repair. Circulation 2010;122:2419-2429. 